2. To: (Receiving Organization)

Distribution

5. Proj./Prog./Dept./Div.:

Spent Nuclear Fuel Project

8. Originator Remarks:

EPT fito transmittal for approval and release. Document is OCRWM related DRD $12 / 9$ la9
11. Receiver Remarks:
11A. Design Baseline Document? [] Yes [X] No

3. From: (Originating Organization)
Process Engineering
6. Design Authority/ Design Agent/Cog. Engr.:
D. R. Duncan

4. Related EDT No:

$$
\text { N/A }
$$

7. Purchase Order No.

N/A

9. Equip./Component No.:

N/A

10. System/Bldg./Facility:

SNF Project

12. Major Assm. Dwg. No.:

N/A

13. Permit/Permit Application No.

N/A

14. Required Response Date:

ASAP

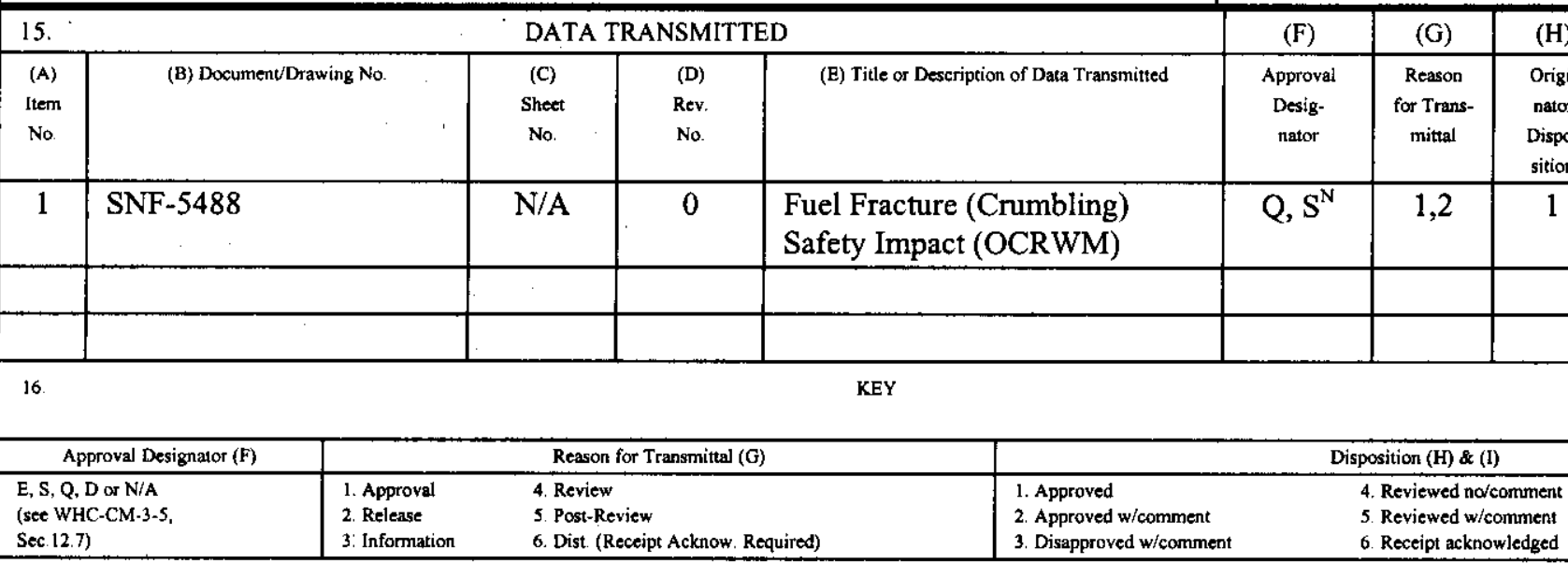

17. SIGNATURE/DISTRIBUTION

(See Approval Designator for required signatures)

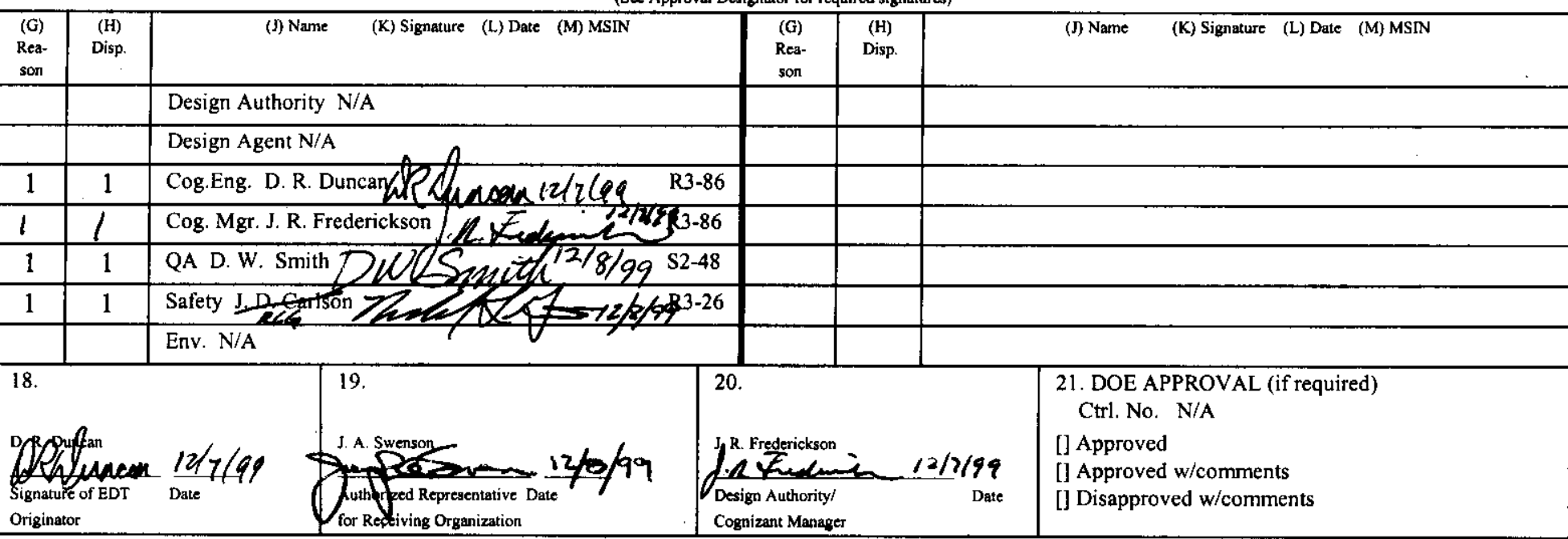

BD-7400-172-2 (05/96) GEF097 


\title{
FUEL FRACTURE (CRUMBLING) SAFETY IMPACT (OCRWM)
}

\author{
M. G. Plys ${ }^{\star}$ and D. R. Duncan \\ Fluor Daniel Hanford Company, Richland, WA 99352 \\ U.S. Department of Energy Contract DE-AC06-96RL13200 \\ EDT/ECN: 627125 \\ UC: 510 \\ Org Code: 87100 \\ Charge Code: 105355 \\ B\&R Code: EW7040000 \\ Total Pages: \\ 19
}

Key Words: Spent Nuclear Fuel, Crumbling, TGA, Oxidation, Reaction Rate

Abstract: The safety impact of experimentally observed $\mathrm{N}$ Reactor fuel sample fracture and fragmentation is evaluated using an average reaction rate enhancement derived from data from thermo-gravimetric analysis (TGA) experiments on fuel samples. The enhanced reaction rates attributed to fragmentation were within the existing safety basis.

* Fauske \& Associates, Inc.

TRADEMARK DISCLAIMER. Reference herein to any specific commercial product, process, or service by trade name, trademark, manufacturer, or otherwise, does not necessarily constitute or imply its endorsement, recommendation, or favoring by the United States Government or any agency thereof or its contractors or subcontractors.

Printed in the United States of America. To obtain copies of this document, contact: Document Control Services, P.O. Box 950, Mailstop H6-08, Richland WA 99352, Phone (509) 372-2420; Fax (509) 376-40909.
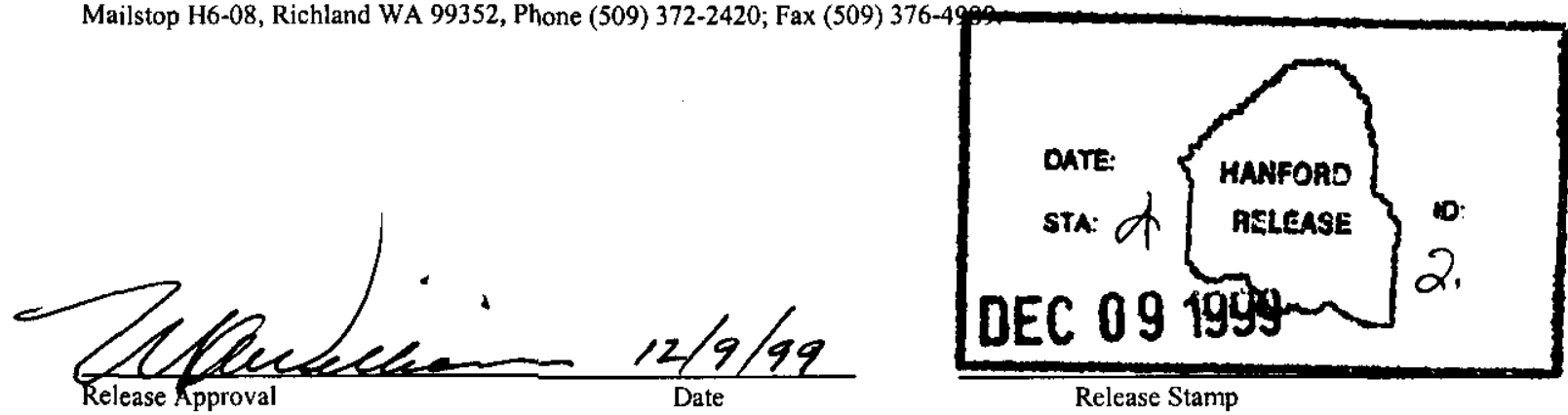

Release Stamp 
FAUSKE \& ASSOCIATES, INC.

\section{CALCULATION NOTE COVER SHEET}

SECTION TO BE COMPLETED BY AUTHOR(S):

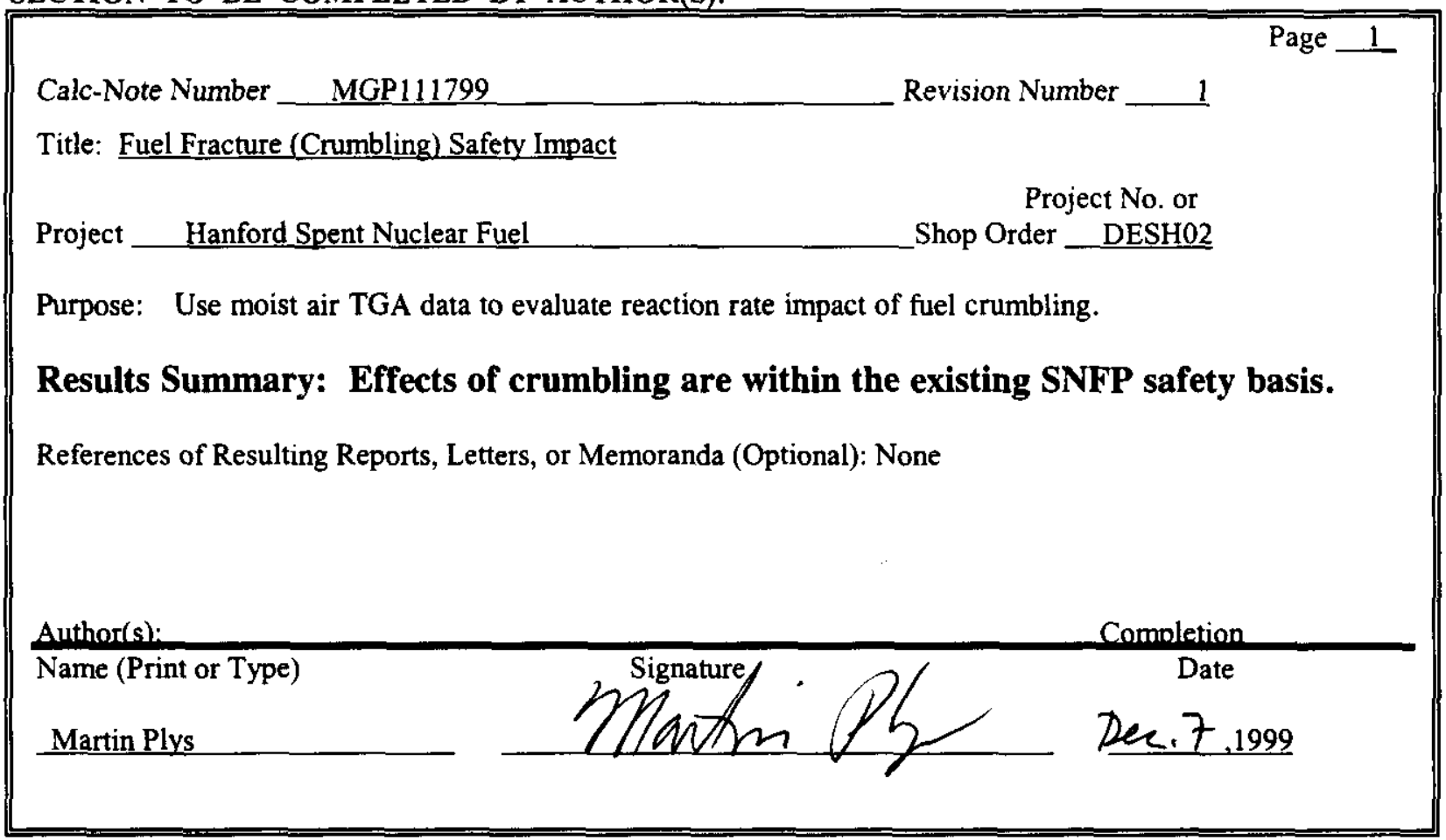

\section{SECTION TO BE COMPLETED BY VERIFIER(S):}

Verifier(s):
Name (Print or Type)
Michael Epstein
Method of Verification: Design Review ___, Alternate Calculations__

\section{SECTION TO BE COMPLETED BY MANAGER:}

\begin{tabular}{|l|l|l|l|l|}
\hline Responsible Manager: \\
Name (Print or Type) \\
Martin Plys
\end{tabular}




\section{CALCULATION NOTE METHODOLOGY CHECKLIST}

1. Is the subject and/or the purpose of the design analysis clearly stated?

2. Are the required inputs and their sources provided?

3. Are the assumptions clearly identified and justified?

4. Are the methods and units clearly identified?

5. Have the limits of applicability been identified?

6. Are the results of literature searches, if conducted, or other background data provided?

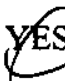

7. Are all the pages sequentially numbered and identified by the calculation note number?

8. Is the project or shop order clearly identified?

KES NO

9. Has the required computer calculation information been provided? YES

NO

N/R

10. Were the computer codes used under configuration control?

YES

NO

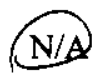

11. Were the computer code(s) used applicable for modeling the physical and/or computational problems identified?....

(Is the correct computer code being used for the intended purpose.)

12. Are the results and conclusions clearly stated?

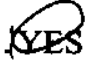

NO

13. Are Open Items properly identified YES

NO

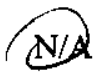

14. Were approved Design Control practices followed without exception?

(Approved Design Control practices refers to guidance documents within NSD that state how the work is to be performed, such as how to perform a LOCA analysis.)

15. Have all related contract requirements been met?

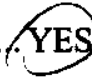

NO

N/A

NOTE: If NO to any of the above, Page Number containing justification: 


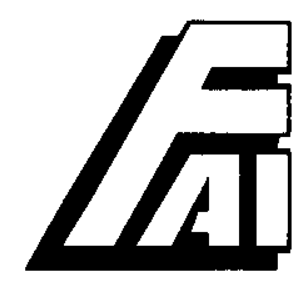

Fauske \& Associates, Inc.

DATE: December 7, 1999

TO: $\quad$ Darrel Duncan, Jim Frederickson, Al Pajunen, and Joe Swenson, Hanford Spent Nuclear Fuel Project

FROM: Martin Plys $\mathrm{MnO}$

SUBJECT: Fuel Fracture (Crumbling) Safety Impact

\subsection{SUMMARY}

This memorandum evaluates the safety impact of experimentally observed $\mathrm{N}$ reactor fuel sample fracture and fragmentation using a technique that relies solely upon observations and is independent of theories for underlying cause. Data and theories are briefly summarized to introduce and motivate the approach.

Moist helium thermogravimetric analysis (TGA) data are used to derive an average reaction rate which is above average, i.e. an average enhancement factor. The frequency of the above-average reaction rates is also derived. Combining these leads to an overall enhancement factor to apply, regardless of fundamental cause.

The analysis is not claimed to be statistically robust because TGA experiments were not designed to look for fragmentation or its effects, and because variability is expected in the character of samples, so that the number of observations necessary to draw precise quantitative conclusions is not known. However, the effect of fragmentation based on current experimental data is small compared with the safety margin used in SNFP calculations.

An extra factor of 1.0 should be added to the reaction rate to account for peak reaction rates observed in TGA experiments. For example, when a safety-basis factor of 10 is applied 
to reaction rates, $10+1=11$ would be appropriate for a long-term average. In contrast the current safety basis was made using an incremental factor of 12 to account for rapid weight gain events, so SNFP safety basis calculations for cold vacuum drying employ an overall enhancement factor of $10+12=22$. So the extra contribution due to above-average reaction rates is an order of magnitude less than the factor applied for rate law uncertainty, and an order of magnitude less than the incremental factor applied for rapid reaction rates.

An underlying cause of fragmentation is believed by the present author, and by authors of reference documents, to be oxidation. The rate and amount of fragmentation is therefore lower at CVD temperatures than at temperatures used for moist helium TGA experiments. Therefore the present assessment, using these TGA data, is conservative.

Fragmentation implies an increase of reaction area with time. The area increase is directly proportional to the amount of oxidation, presuming that oxidation is an underlying cause. Therefore, any increases in reaction rate to account for this effect should be initially zero in a calculation. The safety basis rate law multipliers discussed above are applied at all times during calculations, and therefore the calculations are conservative.

\subsection{N REACTOR FUEL SAMPLE FRACTURE AND FRAGMENTATION DATA}

\subsection{Summary of Observations and Inferences}

Oxidation rate data for $\mathrm{N}$ reactor fuel in dry air and moist helium atmospheres were obtained at PNNL using TGA and are reported in [Trimble, 1999] and [Abrefah, 1999]. Oxidation and fuel fracture with partial fragmentation, colloquially called crumbling, are also discussed by [Ballinger, Loscoe, and DeVine, 1999].

Oxidation rates for $\mathrm{N}$ reactor fuel in moist helium follow first-order Arrhenius kinetics as expected a priori. However, values for the rates fall somewhat below literature values. This is explained in the references as a result of some oxygen contamination in the system. For practical purposes, $\mathrm{N}$ reactor fuel oxidation rates in moist helium are therefore wellrepresented by literature values.

In moist helium atmospheres, specimen fracture and partial fragmentation was observed in some TGA experiments conducted at $160^{\circ} \mathrm{C}$ and above, but not in experiments at lower temperatures. In particular fracture occurred in TGA runs 80,81 , and 82 at a nominal $160^{\circ} \mathrm{C}$. 
Various hypotheses have been postulated for fracture and are described in the following section. TGA experiments were not designed to investigate fracture or provide data to support model development. For example, it is difficult to infer when fracture occurred. In TGA 80, a period of relatively high rate of weight gain, followed by a slight but noticeable change in slope, is evident at about 1300 minutes. This is an expected signature of fracture with partial fragmentation. Unfortunately, the rate of weight gain in TGA 82 was relatively constant, and the weight gain history for TGA 81 was marred by a series of weight loss events.

Observations pertinent to this work are:

1. While there appears to be a temperature threshold effect for fracture and fragmentation, this could be an artifact of experiment duration. It is difficult to tell from the data whether the threshold should really be a relationship between time and temperature. Fragmentation was observed at about the same temperature range for moist helium experiments and dry air experiments.

2. Fragmentation is localized to portions of the specimens, although we cannot a priori discern whether experimental duration or sample characteristics are a cause. There are generally distinct portions of the original specimen that did not crumble, even on originally exposed surfaces, and crumbled fragments that therefore represent a fraction of the original specimen.

3. Fragment sizes are generally visible to the naked eye and are orders of magnitude greater than the fuel grain size.

4. New surface area of fuel fragments is comparable to the original specimen reactive area. This is based on a visual estimate of the fraction of specimen mass that is fragmented, and observations of particle size discussed below. The implication here is that it is difficult to conclusively infer a fragmentation event from inspection of sample weight gain history. Also, experiment duration may influence this observation.

5. It is difficult to determine if fracture is a discrete event during TGA tests, or a series of events that approximates a continuous process. For example, the weight gain history of TGA 80 suggests one major such event and a few minor events, while TGA 81 has continuous noise that suggests frequent fragmentation. TGA 82 data appear to have similar noise, but are not plotted on an appropriate scale to compare with TGA 81 . 


\subsection{Particle Size Data}

A combination of weight gain and particle size data are available at this time for TGA tests conducted in moist helium at a nominal $160^{\circ} \mathrm{C}$; these are TGA runs 80,81 , and 82 . These data are:

Table 2-1. TGA Data for Runs at $160^{\circ} \mathrm{C}$ in Moist Helium

$\begin{array}{lllll}\begin{array}{l}\text { TGA } \\ \text { Run }\end{array} & \begin{array}{l}\text { Surface } \\ \text { Area, } \\ \mathrm{cm}^{2}\end{array} & \begin{array}{l}\text { Initial } \\ \text { Weight } \\ \mathrm{mg}\end{array} & \begin{array}{l}\text { Weight } \\ \text { Gain } \\ \mathrm{mg}\end{array} & \begin{array}{l}\text { Average } \\ \text { Particle Size } \\ \text { micron }\end{array} \\ 80 & 1.24 & 1626 & 33 & 852 \\ 81 & 1.59 & 2649 & 3^{*} & 1160 \\ 82 & 1.94 & 3244 & 36 & 896\end{array}$

*Partial sample loss during experiment.

Note that in TGA 81 the oxidation rate obtained during time periods without sample loss was between values obtained for runs 80 and 82 .

Figure 2-1 contains a particle histogram from combined TGA runs 80,81 , and 82 data reported by [Abrefah, 1999]. The largest particles, near and above 4000 microns, account for most of the mass and surface area. The average size reported by Abrefah and appearing in Table 2-1 is the numerical average of data in Figure 2-1. The surface area mean particle size turns out to be larger than the numerical average by a factor of about two, and it is this value which is of interest in extrapolating reactive area from experiment to application. 
Figure 2-1. Particle counts from PNNL TGA runs 80, 81, 82.

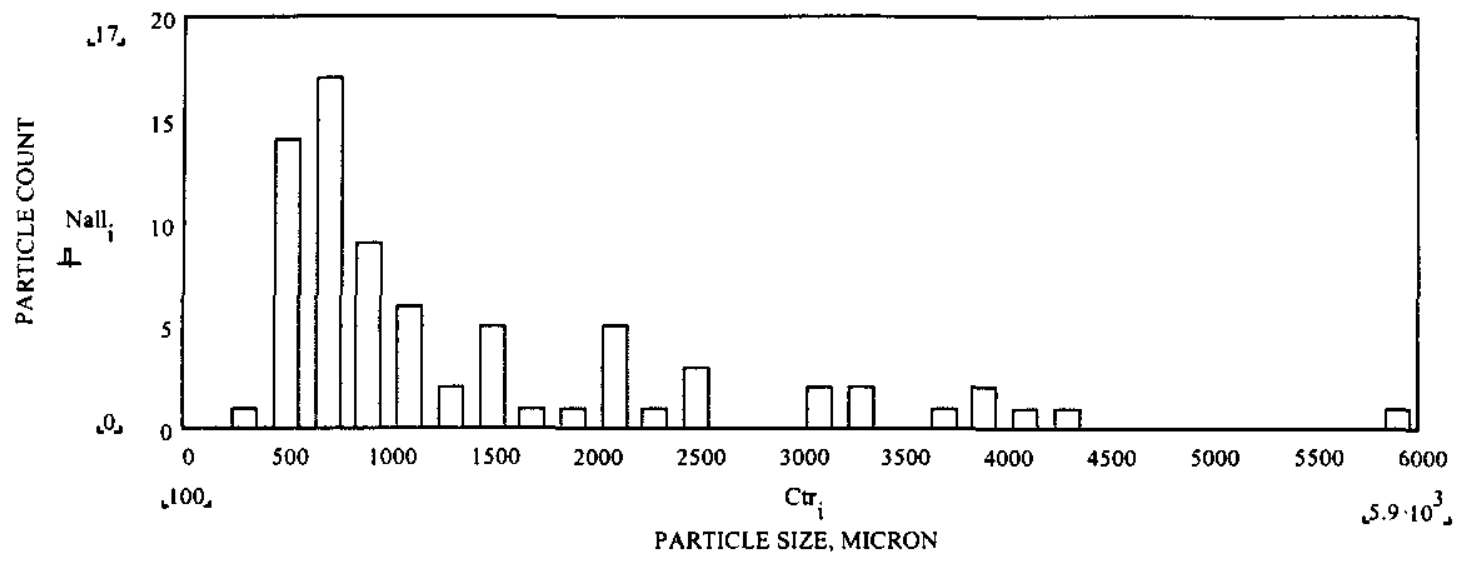

The fraction of material that is crumbled is not available. Ballinger, Loscoe, and DeVine have opined that about $1 / 3$ of the sample mass is fragmented based on post-test photographs for TGA 80 and 81 , and about $3 / 4$ for TGA 82 .

The new reaction area due to fragmentation can be estimated from the above figures. For TGA 80 , using an average particle diameter of 850 microns $=0.085 \mathrm{~cm}$, the area/volume ratio is $A / V=6 / d=71 \mathrm{~cm}^{-1}$. The crumbled volume is estimated using the fraction of $1 / 3$, yielding $1 / 3 * 1.626 / 19=0.028 \mathrm{~cm}^{3}$. The particle area is the product of these values, about $2.0 \mathrm{~cm}^{2}$, which is a factor of 1.6 larger than the original area of $1.24 \mathrm{~cm}^{2}$. Since the particle area is comparable to the original reaction area, it is difficult to discern the effect of fragmentation during the course of these TGA experiments.

\subsection{HYPOTHESES FOR FUEL FRACTURE AND FRAGMENTATION}

Two hypotheses for fuel fracture and fragmentation are presented to date, those of [Ballinger, Loscoe, and DeVine, 1999] and [Abrefah, 1999]. The former hypothesis, known hereafter as the Technical Assistance Group (TAG) crumbling model, is developed into a mathematical model for application to TGA experiments and MCO behavior. The latter hypothesis, known hereafter as the PNNL crumbling concept, consists of a mechanistic cause for fragmentation but is not quantified into a mathematical model at the present time. 


\subsection{PNNL Concept}

In the PNNL concept, microcracks are present in the uranium matrix of corroded or damaged regions of $\mathrm{N}$ reactor fuel. These cracks have been observed and are clearly seen in photomicrographs [Marschman, Pyecha, and Abrefah, 1997] to extend on a scale of at least millimeters through fuel. The PNNL concept is that these microcracks are the underlying contributor to fracture and fragmentation of samples during oxidation. These cracks propagate during oxidation; cracks are initially much larger than grain sizes, and cracks may also propagate along grain boundaries. Particulate varies in size depending on the density of the crack network.

Not stated, but evidently implied by the PNNL references, oxidation in the cracks causes stresses which cause crack propagation and ultimately fragmentation. Stresses are due to the low density of the oxide product compared to that of the metal, about a factor of two. Buildup of oxide in the cracks causes stresses that cannot be borne by the small samples which are not constrained mechanically, for example by cladding.

\section{2 $\quad \underline{\text { TAG Model }}$}

The TAG crumbling model also identifies stresses due to oxidation as the mechanism for fragmentation. Fuel is represented as an ensemble of "cells" that correspond roughly to the grain size of the material. Residual stresses from irradiation damage exist but are balanced in the fuel before oxidation. Oxidation along cell boundaries increases the stress and causes crack tip propagation. A crack propagates when the "oxide wedge" between adjacent cells has grown to a critical thickness called the crack tip opening displacement, or CTOD. When this threshold amount of oxide is built up, a fuel fragment is released. The fuel fragment size is much greater than the cell size, and corresponds to observations.

The model assumes that fragmentation occurs on a fraction of the original specimen exterior reactive surfaces that is not a priori known because the residual stresses are not a priori known. For the same reason, it is not possible to a priori predict whether a given specimen will fragment. Parameters that determine the CTOD are shown to depend strongly on physical properties and irradiation-induced effects that are not a priori known, and this explains the high variability in TGA results. For example, this explains qualitatively why it is 
possible to observe fragmentation during TGA 80,81 , and 82 , but not at experiments conducted at higher temperature.

On the bottom line, the TAG model predicts a direct proportion between the amount of crumbling and the amount of oxidation. Specifically, the model can be manipulated to derive the ratio: (grams crumbled material) / (grams weight gain due to oxidation). This means that the precise temperature history of a specimen or of fuel in an MCO is not important, just the cumulative effect of all oxidation. The ratio is not dependent upon fragment size. It does depend on two parameters that are difficult to determine, the cell size, which is set equal to the grain size, and a parameter known as the crack tip opening displacement, which is derived from further parameters. Also the TAG model predicts a ratio of new surface area produced per unit of weight gain due to oxidation, and this ratio is directly proportional to fragment size.

\subsection{TEMPERATURE EFFECTS AND REACTION RATE IMPACT OF FRACTURE}

For reasons discussed below, fracture may be considered a random event for the purpose of evaluating its impact. A model could in principle be derived that provides the frequency of above-average reaction rates due to fracture, and incorporates a temperaturedependence in that frequency. Due to the small number of observed fragmentation events, the stochastic fracture concept is not quantified. Instead, the highest above-average reaction rates from the data are examined, and the effect of temperature is quantified to demonstrate that an approach based on TGA data is conservative for process application.

\subsection{Stochastic Fracture Concept}

Both the PNNL concept and the TAG model have in common an appeal to variability in fuel character, whether this is in the density of cracks or in variation of the required crack tip opening displacement. We cannot a priori know these facts for a given specimen. A fuel assembly is for practical purposes an ensemble of hundreds of specimens, and a fuel or scrap 
basket is for practical purposes an ensemble of thousands of specimens. Fragmentation can occur at different times in different locations. We seek an overall average effect of fragmentation events which may be considered randomly distributed in time and place.

Another key feature that the PNNL concept and TAG model share is that the rate of crumbling should depend on temperature because oxidation is the underlying cause. We unfortunately do not have sufficient data at this time to quantity a temperature dependence, although we have fundamental reasons to expect that oxidation is an underlying cause of fracture, and therefore the temperature dependence of oxidation be followed.

If fracture events are imagined to occur with a known frequency, then at any given time the number of fractures is given by the Poisson distribution. For a large number of fractures and for times beyond the arrival time of a first fracture, the total number of fractures is found by the binomial distribution which is well-approximated by the normal distribution.

The effect of fuel fracture is to increase reactive surface area and to increase the reaction rate for a brief period of time, as exemplified by TGA 80 data. Thus a given location in fuel normally has the nominal reaction rate, but periodically endures an increased reaction rate. As stated above, the probability that a set of locations is reacting at a higher rate at the same time is given by the binomial distribution (presuming that the same probability applies at all locations). For any given site, there is an average amount of time spent in the average reaction rate state, and an average amount of time spent in the above-average reaction rate state. At any given moment, there is a probability of transition of state. The transition probabilities between each state are based on these durations.

Increased reaction rates therefore can be simulated as a Markov process similar to the manner in which rapid weight gain events in dry air TGA experiments were simulated, without explanation of underlying cause due to conflicting hypotheses and lack of data [Duncan and Plys, 1998]. The fraction of independent reaction sites experiencing above-average reaction rates is equal, in the long run, to the fraction of the time that any given site experiences an 
SNF-5488, Rev. 0

Fuel Fracture (Crumbling)

above-average reaction rate. For short periods of time, it is possible that a larger fraction of reaction sites is reacting at the above-average rate. This fraction increases as the period for time-averaging decreases, or as the number of sites for averaging decreases. All these aspects are included in the Markov process concept.

The concepts presented above provide an appealing way to represent the impact of fuel fracture on reaction rates. However, to turn the stochastic fracture concept into a model requires analysis of the TGA data, and the data were not intended for this purpose. We can infer but not be sure of which increased reaction rates in TGA data represent fracture, and which are due to other reasons, even noise. Thus while this approach was applied to dry air TGA data, it will not be followed through here. Instead, the temperature effect will be examined, and maximum observed reaction rates will be evaluated.

\subsection{Temperature Effect on Fracture}

An estimate of the average arrival time for a fracture is required to quantify number of fractures. The average arrival time must depend upon temperature based on the above discussion. The reaction rate of fuel in an MCO is given by the oxygen-free rate law:

$$
\begin{aligned}
& \mathrm{K}(\mathrm{T}, \mathrm{P})=\mathrm{P}^{1 / 2} 2.14 * 10^{4} \exp \left(-\frac{4937}{\mathrm{~T}}\right) \\
& \mathrm{K}=\text { Weight gain, } \mathrm{mg} / \mathrm{cm}^{2} / \mathrm{hr} \\
& \mathrm{P}=\text { Vapor Pressure, } \mathrm{kPa} \\
& \mathrm{T}=\text { Temperature, } \mathrm{K}
\end{aligned}
$$

Therefore the time to first fracture at a lower temperature is related to the time observed at a given temperature, when steam partial pressure is equal, by

$$
\frac{t}{t_{o}}=\exp \left[4937\left(\frac{1}{T}-\frac{1}{T_{0}}\right)\right]
$$


SNF-5488, Rev. 0

Fuel Fracture (Crumbling)

Inserting $\mathrm{T}=75^{\circ} \mathrm{C}=348 \mathrm{~K}$ and $\mathrm{T}_{\mathrm{o}}=160^{\circ} \mathrm{C}=433 \mathrm{~K}$ yields $\mathrm{t} /$ to $=16$. The ratio of rates would be higher if the steam pressure varied with pressure according to the saturation line. However, experimentally used steam pressures were about $7 \mathrm{kPa}$ are representative of the steam pressure expected during vacuum drying.

Therefore, an expected time to fracture during cold vacuum drying is about an order of magnitude longer than the fragmentation time observed in experiments. Bear in mind that we cannot conclusively tell whether there is a temperature threshold effect for fragmentation, and we cannot conclusively tell the characteristic time to fragmentation in TGA experiments. However we have fundamental reasons to conclude that fragmentation must be slower in real practice such as during cold vacuum drying than in the TGA experiments. Therefore any model based solely upon the observations must be conservative. The extent of conservatism is estimated to be about an order of magnitude, based upon the above discussion.

\subsection{Peak Observed TGA Reaction Rates}

For present purposes, it is sufficient to compare a bounding rate of above-average reaction to the safety basis rate previously given for rapid reactions. Base reaction rates (literature correlations) are increased by a factor of 10 to account for uncertainty in SNFP calculations. An incremental factor of 12 is added to account for above-average reaction rates that may periodically occur. The total rate used in the safety basis is the sum of the constant and rapid reaction effects, $10+12=22$.

Data for this assessment were assembled by Al Pajunen of the SNFP [Pajunen, 1999] and are in Appendix A.

Consider first TGA experiments 80,81 , and 82 which were described in detail above. The highest peak rate in TGA 80 was 21 times the average, over a duration of about 50 minutes, or $2 \%$ of the total experiment duration. Other peak to average rate ratios are much lower. The frequency-averaged peak rate ratio may be defined by summing each individual 
SNF-5488, Rev. 0

Fuel Fracture (Crumbling)

Page 13

December 7, 1999

Safety Impact

of 18

Calc. MGP111799

Rev. $l$

rate ratio times its duration and normalizing by all above average durations: $\sum \Delta t_{i} R_{i} / \sum \Delta t_{i}$. The result for TGA 80 is an average of 3.60 over a total duration of 700 minutes out of 2700 minutes. One way to translate this to an average over the whole experiment is to derive an effective incremental rate multiplier as $(700 / 2700) *(3.60-1.0)=0.68$ or about 0.70 . This ignores times when the overall reaction rate is below average. Clearly an extra incremental factor of 1.0 on the rate, to multiply an effective rate of reaction by 2.0 , bounds the effect of these above-average rates when applied over the duration of a whole experiment. Examining TGA 81 , only modest increments of a factor of 1.3 above average were observed, and this is not worth further pursuit to establish bounding behavior. Examining TGA 82, a frequencyaveraged above-average rate is by inspection about 1.7 (it is somewhat lower) and again results from TGA 80 bound these.

Turning to other experiments, the highest ratio of peak to average rates is 41 , and it occurred for 50 minutes out of 8600 during TGA 95 , i.e. less than $1 \%$ of the duration of this single experiment alone. TGA 95 in fact has the highest set of peak to average rates among those in the table, and provides a bounding case. The frequency-averaged peak rate ratio is about 4. These occur over a total of 2850 minutes out of 8600 , i.e. about $1 / 3$ of the experiment. So the time-averaged value of all above average rates is only about $(2850 / 8600)$ * $(4-1)=$ about 1.0 .

The next highest above average rate is found in TGA 77 , where a rate ratio of 33 is observed for 25 minutes out of 4700 , or about $0.5 \%$ of the experiment duration. For TGA 77, the frequency-averaged peak rate is 3.1. The total duration of these above average rates is 2175 minutes out of 4700 total minutes, about $46 \%$ of the total time, so the time-averaged value of all above-average events is about $(2175 / 4700) *(3.1-1)=$ about 1.0 again.

Without performing a detailed analysis of every experiment, it is clear that an enhancement factor of 2 bounds the observations. That is, the above-average increment is bounded by an increment of 1.0, and above-average rates are bounded by a factor equal to the underlying rate. 
The incremental factor of 1.0 derived here is much less than the incremental factor of 12 derived in the reference document for the safety basis. Even the largest average of aboveaverage rates, about 4.0 from TGA 95-- without regard to the fact that this should only be applied to a fraction of the time -- is still below the incremental factor of 12 used in the safety basis.

Based on the assessment above, there is no need to examine these reaction rates in the same level of detail as in the reference.

For the following reasons, I conclude that fuel reaction rates due to fragmentation during cold vacuum drying are within the existing SNFP safety basis:

1. Extrapolating experimental data, the time to fuel fracture and accompanying fragmentation during cold vacuum drying is about an order of magnitude greater than observed in experiments. Therefore, an experimentally-based approach is conservative.

2. Examining experimental data for the frequency and magnitude of above-average reaction rates, the peak above-average reaction rate (while above-average reactions occur) is about 4 times the average reaction rate. This is within the incremental factor of 12 used in the current safety basis. Considering the frequency of above-average reactions, an increment of 1.0 , equal to the average, should be applied.

3. Experimental data imply an increase of reactive area about equal to the original reactive area over a duration equal to that of cold vacuum drying, and at much higher temperature. This is equivalent to an incremental factor of 1.0 .

4. The analysis is recognized to not be statistically rigorous because TGA experiments were not designed to look for or quantify effects of fragmentation. For this reason a numerical analysis of all the data was not conducted here, only worst case examples 
SNF-5488, Rev. 0

Fuel Fracture (Crumbling)

were chosen. However, experimental observations are well within the current safety basis which assumes a rate law uncertainty factor of 10 plus a rapid reaction contribution of 12 , for a total of $10+12=22$. The incremental factor of 1.0 suggested by experimental data is an order of magnitude less than either contribution to the safety basis.

\subsection{REFERENCES}

Abrefah, J., PNNL, letter to D.J. Trimble, Numatec Hanford Company, Letter Report: Particle Sizes of Disintegrated SNF Samples from TGA Oxidation Testing in Moist Helium, Sep. 17, 1999.

Abrefah, J. and Sell, R.L., Oxidation of K-West Basin Spent Nuclear Fuel in Moist Helium Atmosphere, PNNL-12167, Pacific Northwest National Laboratory, Richland, WA, 1999.

Ballinger, R.G., Loscoe, P.G., and DeVine, J.C., N Reactor Spent Nuclear Fuel Crumbling: Analysis and Modeling, SNFPR 99-01, Rev. 3, Nov. 18, 1999, EDT \# 628219.

Duncan, D.R., and Plys, M.G., Simulation of Normal and Off-Normal Multi-Canister Overpack Behavior, HNF-2256, Rev. 2, DE\&S Hanford, Inc., Richland, WA, 1998 (b).

Marschman, S.C., Pyecha, T.D., and Abrefah, J., Metallographic Examination of Damaged N Reactor Spent Nuclear Fuel Element SFEC5,4378, PNNL-11438, Pacific Northwest National Laboratory, Richland, WA, 1997.

Pajunen, A.L., Rapid Reaction Episodes from N Reactor Fuel Oxidation Tests in Moist Helium, SNFP Memorandum to J.R. Frederickson, 99-SNF/ALP-001, Numatec Hanford, Richland, WA, Nov. 11, 1999.

Trimble, D.J., Oxidation Kinetics of K Basin Fuel, HNF-4206, Duke Engineering \& Services Hanford, Inc., Richland, WA, March, 1999. 
SNF-5488, Rev. 0

Fuel Fracture (Crumbling)

Page 16

December 7, 1999

Safety Impact

of 18

Calc. MGP111799

Rev. 1

APPENDIX A. Excerpt from "Rapid Reaction Episodes from N Reactor Fuel Oxidation

Tests in Moist Helium" by A.L. Pajunen [Pajunen, 1999]. 
SNF-5488, Rev. 0

Fuel Fracture (Crumbling)

Safety Impact
Page 17

of 18
December 7, 1999

Calc. MGPI11799

Rev. 1

J. R. Frederickson

99-SNF/ALP-001

Page 2

November 11, 1999

Table 1. Summary of Potential Rapid Reaction Episodes in Moist Helium TGA Experiments

\begin{tabular}{|c|c|c|c|c|c|c|}
\hline Run & $\begin{array}{l}\text { Temperature, } \\
{ }^{\circ} \mathrm{C}\end{array}$ & $\begin{array}{c}\text { Total Run } \\
\text { Duration, } \\
\text { min }\end{array}$ & Episode & $\begin{array}{l}\text { Duration, } \\
\text { min }\end{array}$ & $\begin{array}{c}\text { Episode } \\
\text { Rate, } \\
\mathrm{mg} / \mathrm{min}\end{array}$ & $\begin{array}{c}\text { Episode Rate } \\
\text { Run Linear } \\
\text { Rate }\end{array}$ \\
\hline \multirow{5}{*}{80} & \multirow{5}{*}{161} & \multirow{5}{*}{2700} & 1 & 100 & 0.068 & 5.3 \\
\hline & & & 2 & 50 & 0.267 & 21 \\
\hline & & & 3 & 125 & 0.031 & 2.5 \\
\hline & & & 4 & 150 & 0.020 & 1.6 \\
\hline & & & 5 & 275 & 0.018 & 1.4 \\
\hline \multirow{2}{*}{81} & \multirow{2}{*}{161} & \multirow{2}{*}{2580} & 1 & 50 & 0.0182 & 1.3 \\
\hline & & & 2 & 50 & 0.0176 & 1.3 \\
\hline \multirow{10}{*}{$82^{*}$} & \multirow{10}{*}{160} & \multirow{10}{*}{2700} & 1 & 100 & 0.022 & 1.6 \\
\hline & & & 2 & 100 & 0.024 & 1.7 \\
\hline & & & 3 & 100 & 0.024 & 1.7 \\
\hline & & & 4 & 100 & 0.024 & 1.7 \\
\hline & & & 5 & 100 & 0.024 & 1.7 \\
\hline & & & 6 & 100 & 0.024 & 1.7 \\
\hline & & & 7 & 150 & 0.0146 & 1.1 \\
\hline & & & 8 & 50 & 0.0189 & 1.4 \\
\hline & & & 9 & 100 & 0.0189 & 1.4 \\
\hline & & & 10 & 100 & 0.0227 & 1.6 \\
\hline 83 & 100 & 3050 & 1 & 50 & 0.0017 & 1.3 \\
\hline \multirow{3}{*}{84} & \multirow{3}{*}{99} & \multirow{3}{*}{2950} & 1 & 150 & 0.0024 & 2.0 \\
\hline & & & 2 & 75 & 0.0014 & 1.2 \\
\hline & & & 3 & 50 & 0.0026 & 2.2 \\
\hline \multirow{5}{*}{85} & \multirow{5}{*}{99} & \multirow{5}{*}{2950} & 1 & 250 & 0.0013 & 3.3 \\
\hline & & & 2 & 300 & 0.0013 & 3.3 \\
\hline & & & 3 & 100 & 0.0056 & -14 \\
\hline & & & 4 & 520 & 0.0007 & 1.8 \\
\hline & & & 5 & 75 & 0.0014 & 3.5 \\
\hline \multirow{2}{*}{86} & \multirow{2}{*}{133} & \multirow{2}{*}{2900} & 1 & 100 & 0.0028 & 1.2 \\
\hline & & & 2 & 50 & 0.0056 & 2.3 \\
\hline 88 & 162 & 2700 & \multicolumn{4}{|c|}{$\begin{array}{l}\text { No episodes with slope greater than rate reported for } \\
\text { test }\end{array}$} \\
\hline \multirow{2}{*}{$89 *$} & \multirow{2}{*}{163} & \multirow{2}{*}{2700} & 1 & 150 & 0.0065 & 1.4 \\
\hline & & & 2 & 150 & 0.0058 & 1.2 \\
\hline \multirow{4}{*}{$91^{*}$} & \multirow{4}{*}{134} & \multirow{4}{*}{2900} & 1 & 350 & 0.0031 & 2.6 \\
\hline & & & 2 & 500 & 0.0015 & 1.2 \\
\hline & & & 3 & 100 & 0.0039 & 3.3 \\
\hline & & & 4 & 100 & 0.002 & 1.7 \\
\hline \multirow{3}{*}{$92^{*}$} & & & 1 & 750 & 0.0008 & 1.3 \\
\hline & 105 & 2900 & 2 & 450 & 0.0011 & 1.8 \\
\hline & & & 3 & 225 & 0.002 & 3.3 \\
\hline
\end{tabular}


Fuel Fracture (Crumbling)

Safety Impact
SNF-5488, Rér. 0

Page 18

of 18
December 7, 1999

Calc. MGPIII 799

Rev. 1

J. R. Frederickson

99-SNF/ALP-001

Page 3

November 11, 1999

\begin{tabular}{|c|c|c|c|c|c|c|}
\hline Ruin & Temperature, & $\begin{array}{l}\text { Total Run } \\
\text { Duration, } \\
\text { min }\end{array}$ & Episode & $\begin{array}{l}\text { Duration, } \\
\text { min }\end{array}$ & $\begin{array}{l}\text { Episode } \\
\text { Rate, } \\
\text { mg/min }\end{array}$ & $\begin{array}{c}\text { Episode Rate } \\
\text { Run Linear } \\
\text { Rate }\end{array}$ \\
\hline \multirow{5}{*}{$93^{*}$} & \multirow{5}{*}{75} & \multirow{5}{*}{5800} & 1 & 200 & 0.0069 & 17 \\
\hline & & & 2 & 350 & 0.0006 & 1.5 \\
\hline & & & 3 & 200 & 0.0005 & 1.2 \\
\hline & & & 4 & 150 & 0.0006 & 1.5 \\
\hline & & & 5 & 100 & 0.0007 & 1.8 \\
\hline \multirow{7}{*}{$94^{*}$} & \multirow{7}{*}{77} & \multirow{7}{*}{8600} & 1 & 500 & 0.0006 & 2.0 \\
\hline & & & 2 & 300 & 0.0008 & 2.7 \\
\hline & & & 3 & 200 & 0.0009 & 3.0 \\
\hline & & & 4 & 400 & 0.0007 & 2.3 \\
\hline & & & 5 & 75 & 0.0025 & 8.3 \\
\hline & & & 6 & 300 & 0.0005 & 1.7 \\
\hline & & & 7 & 100 & 0.003 & 10 \\
\hline \multirow{7}{*}{$95^{*}$} & \multirow{7}{*}{78} & \multirow{7}{*}{8600} & 1 & 400 & 0.0007 & 2.3 \\
\hline & & & 2 & 50 & 0.0123 & 41 \\
\hline & & & 3 & 200 & 0.0013 & 4.3 \\
\hline & & & 4 & 300 & 0.0022 & 7.3 \\
\hline & & & 5 & 150 & 0.0027 & 9.0 \\
\hline & & & 6 & 1600 & 0.0005 & 1.7 \\
\hline & & & 7 & 150 & 0.0024 & 8.0 \\
\hline $96^{*}$ & 211 & 500 & 1 & 30 & 0.0357 & 1.3 \\
\hline $97^{*}$ & 211 & 500 & 1 & 120 & 0.0188 & 1.2 \\
\hline \multirow{3}{*}{$98 *$} & \multirow{3}{*}{129} & \multirow{3}{*}{2900} & 1 & 125 & 0.0048 & 2.1 \\
\hline & & & 2 & 575 & 0.0028 & 1.2 \\
\hline & & & 3 & 375 & 0.0029 & 1.3 \\
\hline $75^{*}$ & 169 & 2150 & 1 & 150 & 0.0155 & 1.2 \\
\hline \multirow{7}{*}{$77^{*}$} & \multirow{7}{*}{108} & \multirow{7}{*}{4700} & 1 & 25 & 0.0114 & 33 \\
\hline & & & 2 & 550 & 0.0011 & 3.1 \\
\hline & & & 3 & 350 & 0.0011 & 3.1 \\
\hline & & & 4 & 450 & 0.0008 & 2.3 \\
\hline & & & 5 & 350 & 0.0012 & 3.4 \\
\hline & & & 6 & 150 & 0.001 & 2.9 \\
\hline & & & 7 & 300 & 0.0006 & 1.7 \\
\hline \multirow{5}{*}{$79 *$} & \multirow{5}{*}{132} & \multirow{5}{*}{2750} & 1 & 100 & 0.0081 & 12 \\
\hline & & & 2 & 150 & 0.0033 & 4.9 \\
\hline & & & 3 & 375 & 0.0025 & 3.7 \\
\hline & & & 4 & 200 & 0.0021 & 3.1 \\
\hline & & & 5 & 225 & 0.0043 & 6.4 \\
\hline \multirow{3}{*}{$87^{*}$} & \multirow{3}{*}{162} & \multirow{3}{*}{2700} & 1 & 150 & 0.0109 & 2.8 \\
\hline & & & 2 & 400 & 0.0051 & 1.3 \\
\hline & & & 3 & 250 & 0.0046 & 1.2 \\
\hline $90^{*}$ & 162 & 1450 & 1 & 130 & 0.0137 & 1.8 \\
\hline
\end{tabular}

* - Rapid reaction episodes may be attributed to noise or drift in the experimental apparatus. 


\section{DISTRIBUTION SHEET}

\begin{tabular}{|c|c|c|c|c|c|}
\hline \multirow{2}{*}{$\begin{array}{l}\text { To } \\
\text { Distribution }\end{array}$} & \multirow{2}{*}{\multicolumn{3}{|c|}{$\begin{array}{l}\text { From } \\
\text { Process Engineering }\end{array}$}} & \multicolumn{2}{|l|}{ Page 1 of 1} \\
\hline & & & & \multicolumn{2}{|l|}{ Date $12 / 1 / 99$} \\
\hline \multirow{2}{*}{\multicolumn{4}{|c|}{$\begin{array}{l}\text { Project Title/Work Order } \\
\text { Fuel Fracture (Crumbling) Safety Impacts (OCRWM) }\end{array}$}} & \multicolumn{2}{|c|}{ EDT No. 627125} \\
\hline & & & & \multicolumn{2}{|l|}{ ECN No. N/A } \\
\hline Name & MSIN & $\begin{array}{c}\text { Text } \\
\text { With All } \\
\text { Attach. }\end{array}$ & $\begin{array}{l}\text { Text } \\
\text { Only }\end{array}$ & $\begin{array}{l}\text { Attach./ } \\
\text { Appendix } \\
\text { Only }\end{array}$ & $\begin{array}{l}\text { EDT/ECN } \\
\text { Only }\end{array}$ \\
\hline
\end{tabular}

Spent Nuclear Fuel Project

R. L. Boylston

J. D. Carlson

R. D. Crowe

D. R. Duncan (5)

J. R. Frederickson

R. L. Garrett

L. J. Garvin

R. L. McCormack

B. J. Makenas

W. C. Miller

A. L. Pajunen

A. V. Reed

J. A. Swenson

D. J. Trimble

SNF Project Files

SNF Project Training Organization

SNF Project Procedures

DOE/RL

P. G. Loscoe

Offsite

M. G. Plys

Fauske \& Associates

16W070 W. $83^{\text {rd }}$. St.

Burr Ridge, IL 60521

R. G. Ballinger

Altran Corporation

Massachusetts Institute of Technology

451 D Street

Boston, MA 02210
R3-26 X

R3-26 X

R3-26 X

R3-86 X

R3-86 X

R3-26 X

R3-26 X

R3-11 X

H0-40 X

R3-11 X

R3-86 $\quad X$

R3-86 $\quad X$

R3-11 X

H0-40 $\mathrm{X}$

R3-11 X

S2-45

$\mathrm{X} 3-86$

S7-41 $\quad X$

$\mathrm{X}$

$\mathrm{X}$ $x$
$x$ 